Gut, 1985, 26, 43-49

\title{
Incidence of colorectal cancer in proctocolitis: a retrospective study of 959 cases over 40 years
}

\author{
Z MǍ̌ATKA, J NEDBAL, J KOCIÁNOVÁ, J HAVELKA, \\ J KUDRMANN, AND J HENDL
}

From the Departments of Medicine, Institute of Oncology, Department of Biochemistry, Bulovka Hospital, Praha, Czechoslovakia

SUMmARY The incidence of colorectal cancer was studied by the actuarial method in 959 patients with idiopathic proctocolitis seen from 1942 to 1981. Forty five per cent had rectal, 23\% left-sided, and $32 \%$ total involvement of the colon. Six cancers were found: one in the rectal, one in the left-sided, and four in the total form of the disease. The risk of cancer per patient year in total colitis was zero per 2151 patient years in the first decade, 1/462 in the second decade, 1/315 in the third decade, and $1 / 75$ in the fourth decade. The cumulative risk of developing cancer was zero at 10 years of duration of the disease, approximately $5 \%$ at 20 years, $15 \%$ at 30 years, and $20 \%$ at 35 years. This increase in risk of cancer is less than reported in some other series. Geographical differences in the incidence of cancer in proctocolitis could influence the risk and therefore also the long-term management of patients with proctocolitis in different geographical areas.

In contrast with the high incidence of colorectal cancer in idiopathic proctocolitis in Anglo Saxon countries, ${ }^{1}$ this complication appears to be rarer in other areas ${ }^{2}$ including Czechoslovakia.

In 1961 the first case of colorectal cancer was reported $^{3}$ in a study of 414 cases of proctocolitis, 120 of which had total involvement of the colon. In a subsequent study of 1503 cases of proctocolitis treated in 16 hospitals in Czechoslovakia, nine cases of colorectal cancer were found. ${ }^{4}$ Since 1975 seven additional cases have been reported: one from our hospital,${ }^{5}$ four from Brno, ${ }^{6}$ and two from Olomouc; ${ }^{7}$ no case of colorectal cancer was detected in 277 cases of proctocolitis in North Bohemia where the follow up of patients with this disease is well organised. ${ }^{8}$

The total number of colorectal cancer published in Czechoslovakia is 16 out of about 2000 cases of proctocolitis. With regard to the quality of the medical care it is unlikely that more cases would escape recognition. No detailed analysis of malignancies associated with proctocolitis has been, so far, done in this country.

Several authors, however, have shown that a more sophisticated approach should be used to show

Address for correspondence: Zdeněk Mařatka, MD, U5 baterie 40, 162-00 Praha 6, Czechoslovakia.

Received for publication 26 March 1984 statistically the frequency of this complication. ${ }^{9-14}$

Analysis of the low risk of cancer because of proctocolitis has important practical implications on such aspects of management of these patients as: advisability of prophylactic colectomy, preservation of the rectum at ileorectal anastomosis and the design of a satisfactory follow up policy.

The high reported incidence of colorectal cancer in some other countries ${ }^{9-14}$ prompted this investigation. As the incidence of colorectal cancer associated with proctocolitis appears to be low in Czechoslovakia we undertook this study using methods similar to those used by others reporting high incidence of colorectal cancer.

\section{Methods}

PATIENTS

Nine hundred and fifty nine patients with proctocolitis encountered from 1942 to 1981 were studied retrospectively. All were seen either by, or under supervision of the first author (ZM). The patients were referred to this hospital from the whole country especially in the first half of the study when our department was the main referral centre for inflammatory bowel diseases in Czechoslovakia. Later the majority of patients came from Prague and Central Bohemia, and only severe cases were 
referred from the rest of the country.

All patients with total proctocolitis and most of those with left-sided proctocolitis were examined and treated as inpatients, and after discharge were followed in the outpatient clinic for inflammatory bowel diseases. Most patients with rectal proctocolitis were examined and treated as outpatients, some of them were seen only for the diagnosis and were followed in their respective medical centres, and sent for reappraisal, if necessary. The patients who did not attend our outpatient clinic were contacted by letter at approximately 10 year intervals.

The diagnosis of proctocolitis was established on a typical history of passage of blood per rectum, tenesmus and/or diarrhoea, proctoscopic, or sigmoidoscopic evidence of haemorrhagic and/or ulcerative inflammation, inflammatory or ulcerative changes on rectal biopsy, typical changes on barium enema (double-contrast method in the last decennium) in the left-sided and total proctocolitis, bacteriology and parasitology negative for specific agents.

For the diagnosis of proctocolitis to be made rectal involvement on endoscopy and biopsy had to be present.

Within the second half of the study 230 cases of regional enterocolitis (Crohn's disease of the colon and rectum) were diagnosed in our institution according to the usual clinical, radiological, and histological criteria.

Cancer was confirmed histologically in the surgical or necropsy specimens. Care was taken not to confuse cancer secondary to proctocolitis with obstructive colitis proximal to cancer of the rectum or sigmoid.

The extent of proctocolitis was assessed by sigmoidoscopy and barium enema as follows: rectal proctocolitis $=$ sigmoidoscopic evidence of proctocolitis in the rectum, or part of it + normal barium enema appearances in the rest of the colon. Leftsided involvement: sigmoidoscopic evidence of proctocolitis in the recto-sigmoid + radiological evidence of the disease in the sigmoid, or sigmoid and descending colon. Total proctocolitis = sigmoidoscopic evidence of proctocolitis in the rectosigmoid + radiological evidence of the disease in the entire colon, or at least including the transverse colon.

Duration of diseases was derived from analysis of the case records. The onset of proctocolitis was defined as the year in which the first symptoms attributable to proctocolitis were noticed by the patient.

The presentation means the year in which the patient presented himself in our institution.
The year of analysis means either the year of the last follow up, or of proctocolectomy or proctectomy in staged operations, or death.

The duration of proctocolitis was defined as the period from the onset of proctocolitis to the year of analysis; it corresponds to the length of exposure to the risk of colorectal cancer. In patients with operations preserving the rectum, or part of it (ileorectal anastomosis) the duration was calculated in the same way irrespective of colectomy.

The length of follow up was defined as the period from the presentation to the year of analysis.

Statistical methods. The incidence of colorectal cancer was calculated in relation to the extent of involvement of the colon, age, and duration of proctocolitis. The actuarial method as described by Berkson and Gage ${ }^{15}$ and applied to proctocolitis by Devroede et al ${ }^{12} 13 \quad 16$ was used. The data were transferred to the punch cards and processed by computer.

Age-specific incidence rates of cancer of the rectum and colon were computed from the figures established by an epidemiological study in Central Bohemia $^{17}$ which reports exact figures of five year incidence of colorectal cancer in the area from which the majority of our patients originated.

To compare our series with the general population expected number of cases of colorectal cancer was calculated using standardisation by indirect method ${ }^{18}$ for matching with respect to patient years in different age intervals. ${ }^{19}$ The overall assessment was made for the age interval 20-74 years, and also for the age interval 45-74 years, corresponding to the age interval in which the cases of cancer in our series occurred.

The number of cases which might be expected to occur were computed by multiplying each cell of the table of patient years by the appropriate age specific rate. Statistical significance of the difference between total observed and expected values was assessed using the Poisson distribution. ${ }^{20}$

\section{Results}

The 959 patients were classified as follows: rectal proctocolitis $430(45 \%)$, left-sided proctocolitis 224 (23\%), total proctocolitis $305(32 \%)$.

Table 1 gives the sex, age, duration of proctocolitis, length of follow up, and operations in the individual forms of proctocolitis, as well as in the whole population studied.

The length of exposure to the risk of colorectal cancer is presented in Fig. 1 for rectal, left-sided, and total proctocolitis; it was greater than 10 years in $40 \%$ of the patients (Table 1). The same data calculated in patient years are shown in Table 2. 
Table 1 Characteristics of patients studied

\begin{tabular}{|c|c|c|c|c|}
\hline Extent of disease & Rectal & Left & Total & Whole series \\
\hline Patients (no) & 430 & 224 & 305 & 959 \\
\hline $\operatorname{Men}(\%)$ & $39 \cdot 3$ & $44 \cdot 2$ & $43 \cdot 8$ & $41 \cdot 8$ \\
\hline Mean age at onset of PC (yr) & $36 \cdot 4$ & $36 \cdot 1$ & $33 \cdot 6$ & $35 \cdot 5$ \\
\hline Mean age at presentation (yr) & 41 & 40 & 36 & 40 \\
\hline Mean age at year of analysis (yr) & 46 & 47 & 43 & 46 \\
\hline Mean age at diagnosis of CRCa (yr) & $68^{*}$ & $48^{*}$ & 58 & 58 \\
\hline Mean duration of $\mathrm{PC}(\mathrm{yr})$ & $9 \cdot 6$ & $11 \cdot 5$ & $10 \cdot 7$ & $10 \cdot 4$ \\
\hline Duration of $\mathrm{PC}>10$ yr $(\%)$ & 33 & 47 & 40 & 40 \\
\hline Surgical treatment: patients (no) & 3 & 5 & 138 & 146 \\
\hline Proctocolectomy & 0 & 0 & 32 & 32 \\
\hline Colectomy and ileorectal anastomosis & 0 & 0 & 51 & 51 \\
\hline Other operations & 3 & 5 & $55 \dagger$ & 63 \\
\hline
\end{tabular}

$\mathrm{PC}=$ proctocolitis. $\mathrm{CRCa}=$ colorectal cancer.

${ }^{*}$ one case only. $\dagger$ mostly subtotal colectomy and ileostomy.

Six colorectal cancer were detected in the 959 patients: one in 430 patients with rectal involvement, one in 224 patients with left-sided involvement, and four in 305 patients with total involvement (Table 3).

No case of cancer has been detected, so far, among 51 patients living after colectomy and ileorectal anastomosis. The duration of proctocolitis in these patients before colectomy and the length of follow up after it are shown in Table 4.

The details of the patients with colorectal cancer are in Table 5 .

Five tumours were of the usual solitary type: three in the rectum or rectosigmoid, one in the transverse colon and one in the sigmoid colon after colectomy and ileosigmoid-anastomosis. The sixth tumour was multifocal and anaplastic.

As in most other reports cancer was discovered in an advanced stage except for the patient no 5 who nevertheless died three months after removal of the tumour. Four patients developed cancer before

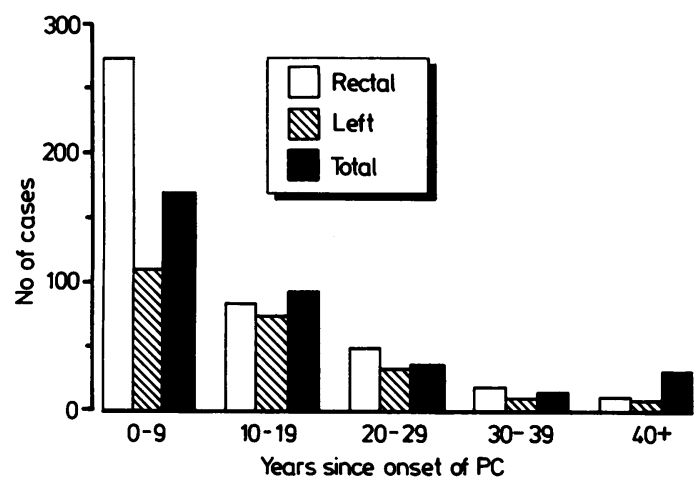

Fig. 1 Length of exposure to the risk of colorectal cancer.
1973 , before the date of introduction of colonoscopy in our hospital.

Five of the six patients with colorectal cancer were operated on: complete removal of the tumour was possible in two; only one survived for one year after the diagnosis of cancer. The sixth cancer was detected only at necropsy.

Two of the six patients had not been seen by us before cancer developed: patient no 1 (Table 5) was

Table 2 Incidence of colorectal cancer related to the duration of proctocolitis in 959 cases with rectal, left sided, and total colonic involvement

\begin{tabular}{|c|c|c|c|c|c|}
\hline $\begin{array}{l}\text { Years since } \\
\text { onset of } P C\end{array}$ & $\begin{array}{l}\text { Patients } \\
\text { (no) }\end{array}$ & $\begin{array}{l}\text { Patient- } \\
\text { years in } \\
\text { period }\end{array}$ & $\begin{array}{l}\text { Cancers } \\
\text { (no) }\end{array}$ & $\begin{array}{l}\text { Incidencel } \\
\text { patient- } \\
\text { year }\end{array}$ & $\begin{array}{l}\text { Risk/ } \\
\text { patient- } \\
\text { year }\end{array}$ \\
\hline \multicolumn{6}{|l|}{ All patients } \\
\hline-9 & 959 & 6731 & 0 & 0 & - \\
\hline $10-19$ & 411 & 2900 & 3 & 0.001 & 1 in 966 \\
\hline $20-29$ & 169 & 1105 & 2 & 0.002 & 1 in 550 \\
\hline $30-39$ & 52 & 310 & 1 & 0.003 & 1 in 310 \\
\hline 40 & 17 & 82 & 0 & 0 & - \\
\hline \multicolumn{6}{|l|}{ Rectal } \\
\hline-9 & 430 & 2940 & 0 & 0 & - \\
\hline $10-19$ & 158 & 1145 & 1 & 0.001 & 1 in 1145 \\
\hline $20-29$ & 75 & 515 & 0 & 0 & - \\
\hline $30-39$ & 26 & 165 & 0 & 0 & - \\
\hline $40-$ & 10 & 56 & 0 & 0 & - \\
\hline \multicolumn{6}{|l|}{ Left sided } \\
\hline-9 & 224 & 1640 & 0 & 0 & - \\
\hline $10-19$ & 117 & 830 & 0 & 0 & - \\
\hline $20-29$ & 45 & 275 & 1 & 0.0036 & 1 in 275 \\
\hline $30-39$ & 12 & 70 & 0 & 0 & - \\
\hline $40-$ & 5 & 20 & 0 & 0 & - \\
\hline \multicolumn{6}{|l|}{ Total } \\
\hline-9 & 305 & 2151 & 0 & 0 & - \\
\hline $10-19$ & 136 & 925 & 2 & 0.002 & 1 in 462 \\
\hline $20-29$ & 49 & 315 & 1 & 0.0031 & 1 in 315 \\
\hline $30-39$ & 14 & 75 & 1 & 0.013 & 1 in 75 \\
\hline 40- & 2 & 6 & 0 & 0 & - \\
\hline
\end{tabular}


Table 3 Colorectal cancer in proctocolitis (PC) 1942 to 1981

\begin{tabular}{llll}
\hline Extent of PC & Patients (no) & Cancers (no) & $\%$ \\
\hline Rectal & 430 & 1 & 0.23 \\
Left sided & 224 & 1 & 0.44 \\
Total & 305 & 4 & 1.31 \\
Whole series & 959 & 6 & 0.63 \\
\hline
\end{tabular}

referred to the surgical department of our hospital for operation of cancer of the rectum and died postoperatively. A retrospective search disclosed that the patient was treated for proctocolitis earlier elsewhere; the diagnosis was supported by the result of sigmoidoscopy and rectal biopsy 11 years before death.

Patient no 6 was admitted as an abdominal emergency. Surgical exploration showed extensive cancer in the abdomen. At necropsy there was a cancer of the hepatic flexure and rectum with multiple metastases. The colon showed chronic ulcerative colitis with inflammatory polyps. The patient had been treated elsewhere for proctocolitis lasting 19 years.

Patient no 5 also was unusual: colectomy and ileosigmoid-anastomosis was carried out elsewhere for proctocolitis; cancer developed in the sigmoid 35 years after onset of proctocolitis.

Table 2 shows the annual risk of developing colorectal cancer expressed as incidence per patient years. In the whole population of colitics studied the risk is zero per 6731 patient years in the first decade, $1 / 966$ in the second decade, $1 / 550$ in the third decade, and $1 / 310$ in the fourth decade. The respective figures for total proctocolitis are: $0 / 2151$, $1 / 462,1 / 315$ and $1 / 75$.

Cumulative probability of survival without developing colorectal cancer was calculated by the actuarial method for total proctocolitis and for all patients. The cumulative probability of survival
Table 4 Length of exposure to the risk of cancer in 51 patients after colectomy and ileorectal anastomosis

\begin{tabular}{lcc}
\hline & $\begin{array}{l}M \\
(y r)\end{array}$ & $\begin{array}{l}S D \\
(y r)\end{array}$ \\
\hline Mean duration of proctocolitis before colectomy & 4 & $\pm 5 \cdot 7$ \\
Mean length of follow up after colectomy & 8 & \pm 6 \\
Mean length of exposure to the risk of cancer & 12 & $\pm 8 \cdot 3$ \\
\hline
\end{tabular}

without cancer was calculated for each year in which a cancer was found (Table 6).

The cumulative probability of developing cancer is shown in Figure 2 for the total proctocolitis and for all patients. Curves could not be constructed for the rectal and left-sided proctocolitis, because there was only one case of cancer in each of these categories.

In order to compare the results with those of other series, the figures at 10,20,30, and 35 years of duration of proctocolitis, were calculated by interpolating data from the curves in Figure 2. Estimates of cancer frequency for the whole series at 10, 20, 30 , and 35 years were $0 \%, 1 \%, 4 \%$, and $5 \%$ respectively, and for those with total colonic involvement $0 \%, 5 \%, 15 \%$, and $20 \%$ respectively.

Observed and age-specific numbers of cases of colorectal cancer and calculated patients-years at risk are given in Table 7 . With respect to the small number of data in individual age categories the comparison is made by means of the total number of cases observed and the sum of cases expected in the categories. This calculation is statistically valid.

The relative risk of developing cancer (calculated by the ratio of observed and expected numbers of cases) is given in the last two columns of Table 7 for example, $2 \cdot 2=6 / 2 \cdot 74$.

The confidence limits for the mean number of cases calculated at $5 \%$ and $1 \%$ level are: $2 \cdot 61-12 \cdot 8$ and 1.78-15.2 respectively for the whole series (six cases), and $1.36-9.58$ and $0.82-15 \cdot 2$ respectively for

Table 5 Characteristics of patients with colorectal cancer

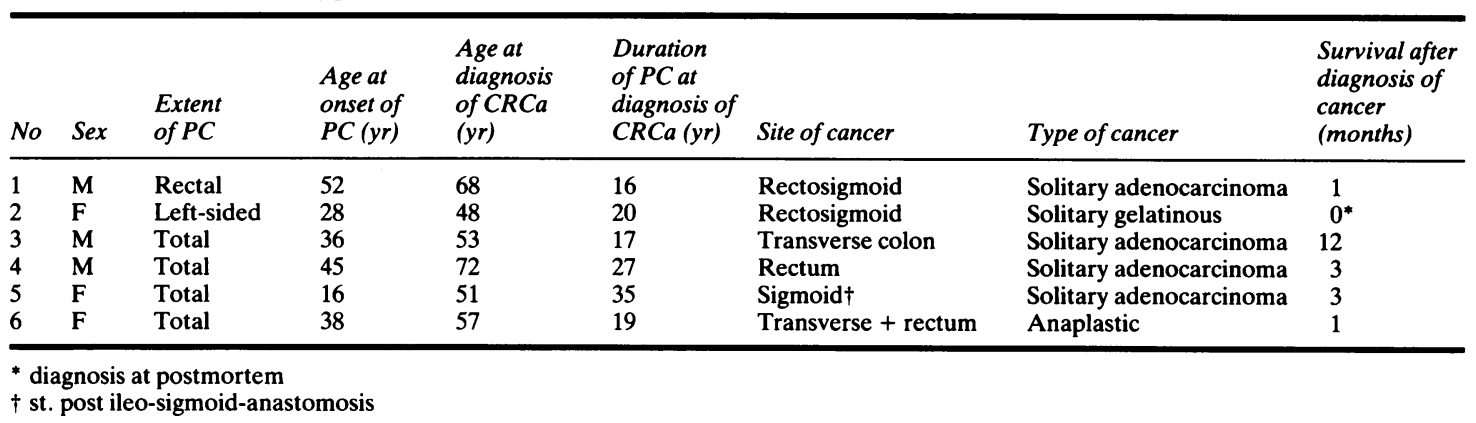


Table 6 Probability of survival without cancer in 959 patients with proctocolitis and in 305 of those with total colonic involvement at each year in which a cancer was observed. Calculated by the actuarial method

\begin{tabular}{|c|c|c|c|c|c|c|c|c|}
\hline $\begin{array}{l}\text { Years since } \\
\text { onset of PC }\end{array}$ & $\begin{array}{l}\text { Patients } \\
\text { (no) }\end{array}$ & $\begin{array}{l}\text { Incomplete } \\
\text { year of } \\
\text { follow-up }\end{array}$ & $\begin{array}{l}\text { Corrected at } \\
\text { risk (no) }\end{array}$ & $\begin{array}{l}\text { Cases of } \mathrm{Ca} \\
\text { (no) }\end{array}$ & $\begin{array}{l}\text { Proportion } \\
\text { with } \mathrm{Ca}\end{array}$ & $\begin{array}{l}\text { Proportion } \\
\text { without } \mathrm{Ca}\end{array}$ & $\begin{array}{l}\text { Cumulative } \\
\text { proportion } \\
\text { without } \mathrm{Ca}\end{array}$ & $S D$ \\
\hline \multicolumn{9}{|l|}{ All patients } \\
\hline up to 9 & 532 & 20 & 522 & 0 & 0 & 1 & 1 & - \\
\hline 16 & 294 & 26 & 281 & 1 & 0.0035 & 0.9965 & 0.9965 & 0.0035 \\
\hline 17 & 267 & 22 & 255 & 1 & 0.0039 & 0.9961 & 0.9957 & 0.0052 \\
\hline 19 & 227 & 30 & 212 & 1 & 0.0047 & 0.9953 & 0.9911 & 0.0070 \\
\hline 20 & 196 & 17 & $187 \cdot 5$ & 1 & 0.0053 & 0.9947 & 0.9858 & 0.0076 \\
\hline 27 & 67 & 7 & $63 \cdot 5$ & 1 & 0.0150 & 0.9850 & 0.9712 & 0.0177 \\
\hline 36 & 36 & 5 & $33 \cdot 5$ & 1 & 0.0292 & 0.9708 & 0.9421 & 0.0321 \\
\hline \multicolumn{9}{|c|}{ Total proctocolitis } \\
\hline up to 16 & 69 & 8 & 65 & 0 & 0 & 1 & 1 & - \\
\hline 17 & 54 & 6 & 51 & 1 & 0.0191 & 0.9809 & 0.9809 & 0.0193 \\
\hline 19 & 44 & 4 & 42 & 1 & 0.0232 & 0.9768 & 0.9542 & 0.0281 \\
\hline 27 & 16 & 4 & 14 & 1 & 0.0713 & 0.9287 & 0.8893 & 0.0682 \\
\hline 36 & 8 & 2 & 7 & 1 & $0 \cdot 1421$ & 0.8579 & 0.7648 & $0 \cdot 1321$ \\
\hline
\end{tabular}

total proctocolitis (four cases).

The risk of cancer was found to be about twice as high in proctocolitis, and four times as high in total proctocolitis, than in the general population. The excess in the relative risk in the whole series lies within the limit of statistical significance. The excess in the total proctocolitis is significant at the $5 \%$ level, but not at the $1 \%$ level.

\section{Discussion}

The paucity of cancers in this series of 959 patients with proctocolitis during 40 years has created the impression that this complication in our population is very rare. The results of this study show that the presence of excess risk of colorectal cancer can be shown by the actuarial method in total proctocolitis. The calculated risk, however, is lower than in other studies. $^{9-14}$

The question arises how reliable are the results within the constraints of this study:

Incomplete follow up of some patients is a defect shared by other similar studies. In spite of this the

Table 7 Observed and expected age-specific number of cases of cancer with patient-years at risk and 'relative risk' of developing colorectal cancer

\begin{tabular}{|c|c|c|c|c|c|c|c|c|c|c|}
\hline \multirow[b]{2}{*}{ Age interval } & \multirow[b]{2}{*}{-39} & \multirow[b]{2}{*}{$40-44$} & \multirow[b]{2}{*}{$45-49$} & \multirow[b]{2}{*}{$50-54$} & \multirow[b]{2}{*}{$55-59$} & \multirow[b]{2}{*}{$60-64$} & \multirow[b]{2}{*}{$65-69$} & \multirow[b]{2}{*}{$70-74$} & \multicolumn{2}{|l|}{ Total } \\
\hline & & & & & & & & & $45-74$ & $20-74$ \\
\hline $\begin{array}{l}\text { All patients } \\
\text { Mortality rate in general population } \\
\quad\left(\text { cases for } 10^{5}\right)\end{array}$ & $2 \cdot 2$ & $14 \cdot 1$ & $17 \cdot 3$ & 52.6 & 82.4 & $91 \cdot 3$ & $150 \cdot 3$ & $171 \cdot 5$ & & \\
\hline Patient-years & 5445 & 1510 & 1384 & 1123 & 773 & 570 & 336 & 148 & 4349 & 11304 \\
\hline Observed (no) & 0 & 0 & 1 & 2 & 1 & 0 & 1 & 1 & 6 & 6 \\
\hline $\begin{array}{l}\text { Expected (no) } \\
\text { 'Relative risk' of developing cancer }\end{array}$ & $0 \cdot 11$ & $0 \cdot 21$ & $0 \cdot 24$ & $0 \cdot 60$ & $0 \cdot 64$ & $0 \cdot 52$ & $0 \cdot 50$ & $0 \cdot 25$ & $\begin{array}{l}2 \cdot 74 \\
2 \cdot 2\end{array}$ & $\begin{array}{l}3.06 \\
1.96\end{array}$ \\
\hline Total proctocolitis & & & & & & & & & & \\
\hline Patient-years & 1823 & 477 & 461 & 384 & 233 & 164 & 94 & 36 & 1372 & 3642 \\
\hline Observed (no) & 0 & 0 & 0 & 2 & 1 & 0 & 0 & 1 & 4 & 4 \\
\hline Expected (no) & 0.04 & 0.07 & 0.08 & 0.20 & $0 \cdot 19$ & $0 \cdot 15$ & $0 \cdot 14$ & 0.06 & $0 \cdot 82$ & 0.93 \\
\hline 'Relative risk' of developing cancer & & & & & & & & & 4.9 & $4 \cdot 3$ \\
\hline
\end{tabular}

If $A_{i}$ means mortality rate in general population in the age interval $i$ (cases for $10^{5}$ ), $B_{i}$ patient-years in the interval $i, C_{i}$ number of cases observed, $D_{i}$ number of cases expected, then: $D_{i}=\frac{A_{i} \times B_{i}}{10^{5}}$

The total cases expected for the age intevals $45-74$ and 20-74 are calculated: $D=\Sigma D_{i}$

The total cases observed for the age intervals $45-74$ and $20-74$ are calculated: $C=\Sigma C_{i}$ 


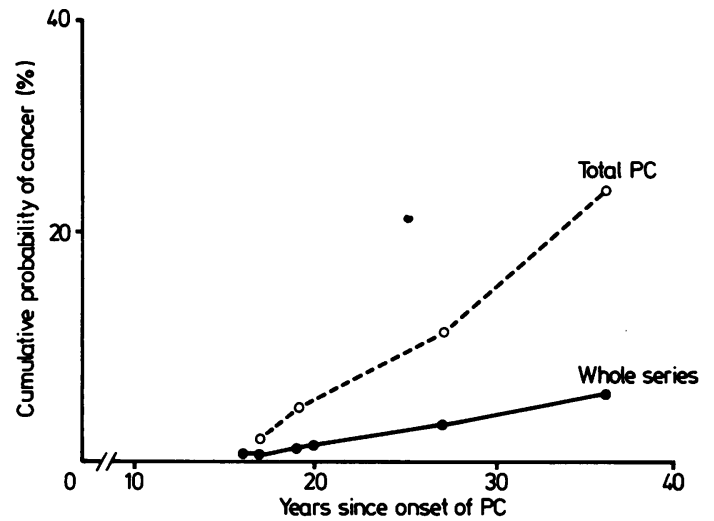

Fig. 2 Cumulative probability of developing colorectal cancer according to the duration of the disease in 959 patients with proctocolitis and in 305 of those with total involvement of the colon.

information drawn from partial follow up is sufficient if adequate statistical methods are applied such as the actuarial method in this study. The patients seen only once were almost exclusively those with rectal form of proctocolitis whereas those with total and most of those with left-sided involvement were followed as long as circumstances permitted.

The objection that almost half the patients with total proctocolitis had a colectomy before cancer had had the time to develop is counterbalanced by the fact that the majority of the colectomised patients were left with the diseased rectum in situ (after ileorectal anastomosis or subtotal colectomy with ileostomy) so that a continuing but reduced risk of cancer has been present.

On the other hand the awareness of the low incidence of cancer in this series made us particularly anxious to search for this complication both within and outside the group of patients followed in our institution. This resulted in collecting patients who would have not come to our attention had our interest in this disease not been known. An example of this are cases 1 and 6 , whom we saw only after cancer had been established by an operation, or necropsy.

In a country like Czechoslovakia in which our institution has served as the referral centre for proctocolitis, especially for its severe cases, it would be unusual to miss the diagnosis of cancer resulting from proctocolitis. Such patients, except for those dying suddenly from unrelated causes, would, almost certainly, have been referred to the specialist centre and subjected to regular sigmoidoscopy and biopsy. Biopsy and colectomy specimens from patients requiring surgery were submitted to detailed and expert histological examination for evidence of mucosal dysplasia or cancer.

Figure 3 shows that the risk of cancer in this series is less than in other published reports. ${ }^{10-14}$ The same is true in patients after colectomy and ileorectal anastomosis. In contrast with the curves published by Baker $e t a l^{21}$ and Grundfest $e t a l,^{22}$ no curve of risk could be constructed in this series, because no case of cancer in the rectal remnant has been found.

The results of this study also differ from other reports in two other aspects: firstly most of the cancers in our patients did not have the features of cancer secondary to colitis - that is, onset in younger age, location in proximal segments of the colon, multicentricity, or higher malignancy. With one exception they were solitary cancers occurring in advanced age, and located in the rectosigmoid.

Secondly, we found cancers also in the rectal and left-sided proctocolitis with frequency corresponding to the expected incidence. In view of the large number of patients with rectal proctocolitis, coincidental occurrence of colorectal cancer could be expected. It is, therefore, surprising that to date only three cases of colorectal cancer in rectal proctocolitis have been reported..$^{19}$ Establishment of colorectal cancer in rectal and left-sided proctocolitis within the expected incidence can be regarded as supporting the validity of the results of this study.

What could account for the differences observed between the incidence and character of colorectal cancer in this population and in other populations studied?

It seems unlikely that the present data might be because of the selection of cases which substantially differ from other studies. As colorectal cancer in this population has been not only rare, but also different from the type of neoplasia associated with proctocolitis and usual location it is possible that a geographical factor is responsible similarly as in

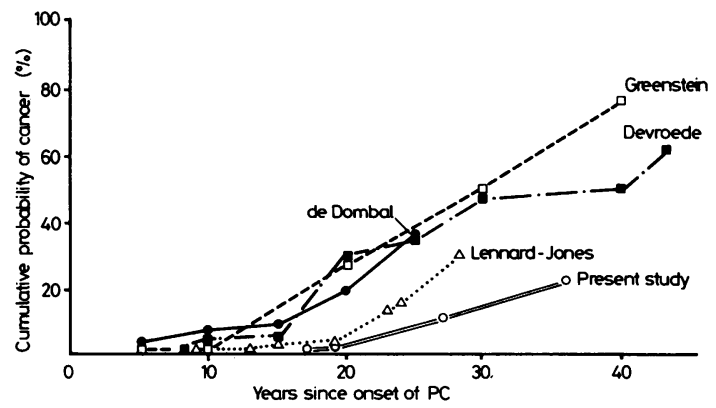

Fig. 3 Risk of colorectal cancer in total proctocolitis: comparison of the results of the studies. 
other areas with low incidence of this complication. ${ }^{2}$

Geographical differences in the epidemiology of colorectal cancer are well established; as they exist in the whole population there is no wonder that they also exist in selected groups like proctocolitis. The reasons for the differences may be environmental, probably dietetic. The composition of the food participates not only in the carcinogenesis of a healthy colon but also and perhaps even more in that of an inflammed colon.

The findings of the present study may be important, because they suggest that the risk of colonic cancer in proctocolitis may differ in different countries and therefore clinical guidelines established on a basis of studies performed on particular populations of colitics may not be universally applicable.

\section{Addendum}

After completing this paper another case of cancer was recorded in an 80 year old man with a 25 year history of rectal proctocolitis. There were two cancers in the sigmoid colon about $15 \mathrm{~cm}$ apart; the distal was probably and the proximal certainly, situated in an area that had never been affected by proctocolitis.

\section{References}

1 Mottet NK. Histopathologic spectrum of regional enteritis and ulcerative colitis. Philadelphia: Saunders, 1971: 220.

2 Gilat T, Rozen P. Risk of colon cancer in ulcerative colitis in low incidence areas - a review. In: Colorectal cancer. Winiwer SJ, Schottenfeld D, Sherlock P, eds. New York, Raven Press, 1980: 335-40.

3 Mařatka Z, Krumlova J. Cancer of the colon in ulcerative colitis: First case in Czechoslovakia. (In Czech). Cesk Gastroenterologie Vyz 1961; 15: 612-4.

4 Mařatka Z, Kudrmann J. Malignant and potentially malignant lesions in chronic inflammatory diseases of the colon and rectum. In: Balneologia et balneotherapie. Carlsbad: Societas medica cecoslovaka, 1975: 9-26.

5 Mařatka Z, Kudrmann J. The risk of malignant change of proctocolitis and its prevention in Czechoslovakia.
(In Czech). In: Progress in gastroenterology, Praha, Avicenum, 1983.

6 Martinek K. Incidence of colorectal cancer in patients with proctocolitis. (In Czech). Vnitř Lék 1982; 28: 45-7.

7 Benysek L, Güttnerova J. Complications in patients with idiopathic proctocolitis and Crohn's disease. (Abstract in Czech). Cesk Gastroenterologie Vyz 1979; 33: 448

8 Bitter J, Hulec J: Ulcerative colitis in Northern Bohemia. (In Czech). Cesk Gastroenterologie Vyz 1980; 34: 137-44.

9 Edwards FC, Truelove SC. The course and prognosis of ulcerative colitis. Part IV. Carcinoma of the colon. Gut 1964; 5: 15-22.

10 de Dombal FT, Watts JM, Watkinson G, Goligher JC. Local complications of ulcerative colitis: stricture, pseudopolyposis and carcinoma of colon and rectum. Br Med J 1966; 1: 1442-7.

11 Lennard-Jones JE, Morson BC, Ritchie JK, Shove DC, Williams CB. Cancer in colitis: assessment of the individual risk by clinical and histological criteria. Gastroenterology 1977; 73: 1280-9.

12 Devroede GJ, Taylor WF, Sauer WG, Jackman RJ, Stickler GB. Cancer risk and life expectancy of children with ulcerative colitis. N Engl J Med 1971; 285: 17-21.

13 Devroede GJ, Taylor WF. On calculating cancer risk and survival of ulcerative colitis patients with the life table method. Gastroenterology 1976; 71: 505-9.

14 Greenstein AJ, Sachar DB, Smith H. Cancer in universal and left-sided ulcerative colitis: factors determining risk. Gastroenterology 1979; 77: 290-4.

15 Berkson J, Gage RP. Calculation of survival rates for cancer. Proc Staff Meet Mayo Clin 1950; 25: 270-86.

16 Devroede G, Taylor WF, Greenstein AJ, Janowitz HD. Comment calculer l'histoire naturelle d'une maladie? Gastroenterol Clin Biol 1979; 3: 259-66.

17 Toman R, Gregor O, Pastorová J, Drnková V: Clinical and epidemiological study of colorectal cancer. Ann Gastroenterol Hépatol 1982; 18: 321-8.

18 Armitage P. Statistical methods in medical research. Oxford, Blackwell, 1971: 388.

19 Prior P, Cyde S, Cooke WT, Waterhouse JAH, Allan RN. Mortality in Crohn's disease. Gastroenterology 1981; 80: 307-12.

20 Sachs L. Angewandte Statistik. Berlin: Springer, 1974.

21 Baker WNW, Glass RE, Ritchie JK, Aylett SO. Cancer of the rectum following colectomy and ileorectal anastomosis for ulcerative colitis. Br J Surg 1978; 65: $862-8$.

22 Grundfest SF, Fazio V, Weiss RA, et al. The risk of cancer following colectomy and ileorectal anastomosis for extensive mucosal ulcerative colitis. Ann Surg 1981; 193: $9-14$. 